\title{
Novel mango bars using gellan gum as gelling agent: Rheological and microstructural studies
}

\author{
Florina Danalache a, b, Paulina Mata a, Margarida Moldão-Martins ${ }^{\text {b }}$, Vitor D. Alves ${ }^{\text {b, * }}$ \\ ${ }^{a}$ REQUIMTE/CQFB, Departamento de Química, Faculdade de Ciências e Tecnologia, Universidade Nova de Lisboa, Quinta da Torre, 2829-516 Caparica, \\ Portugal \\ ${ }^{\mathrm{b}}$ CEER - Centro de Engenharia dos Biossistemas, Instituto Superior de Agronomia, Universidade de Lisboa, Tapada da Ajuda, 1349-017 Lisboa, Portugal
}

\section{A R T I C L E I N F O}

\section{Article history:}

Received 22 April 2014

Received in revised form

21 July 2014

Accepted 9 September 2014

Available online 17 September 2014

\section{Keywords:}

Fruit bars

Mango purée

Gellan

Rheology

Microstructure

\begin{abstract}
A B S T R A C T
This work aimed the development of mango bars, made with fresh mango puree and gellan gum. The influence of gellan concentration as well as the ratio of LA (low-acyl) and HA (high-acyl) gellan on the rheological and microstructural properties of the mango bars was studied. Rheological outcomes showed that both LA and HA, and in mixtures, were able to produce jellified products, within a rather low maturation time. Furthermore, a synergistic effect was observed at different ratios of LA/HA, enabling the production of mango bars with intermediate viscoelastic properties. Higher values of the dynamic moduli were perceived as the LA content increased. Confocal microscopy is in agreement with the rheological results, revealing a weakening of the gel structure with the increasing percentage of HA. Results suggest that $1 \mathrm{~g}$ of LA/HA 50/50 per $100 \mathrm{~g}$ of puree produces structures with suitable mechanical properties. However, the results need to be correlated to texture and sensory analysis, before proceeding to the next steps of product development.
\end{abstract}

() 2014 Elsevier Ltd. All rights reserved.

\section{Introduction}

Changes in modern lifestyle and the growing awareness of the link between diet and health, as well as new processing technologies, have led to a rapid rise in the consumption of fresh fruits products (O'Shea, Arendt, \& Gallagher, 2012). Ready-to-eat fresh fruit products became an important area in the food industry due to their characteristics of freshness, low caloric content, and an active promotion of fruit as a basic component of a healthy diet (Corbo, Lanciotti, Gardini, Sinigaglia, \& Guerzoni, 2000). Therefore, new trends in food industry require the development of new high quality convenient fruit products compatible with a healthy diet.

Fruit and vegetables are processed into a variety of products such as sliced minimally processed fruits, juices and concentrates, pulps and dehydrated products, jams and jellies, pickles, chutneys and fruit bars (Ahvenainen, 1996; Schieber, Wieland, \& Reinhold, 2000). However, it is difficult to obtain a convenient product maintaining the desired stability from a chemical, enzymatic and microbiological point of view and presenting the nutritional and sensory attributes of a fresh product. A key factor on the development of new products relies on the selection of the type of

\footnotetext{
* Corresponding author. Tel.: +351 21 3653546; fax: +351 213653195 .

E-mail addresses: vitoralves@isa.ulisboa.pt, alvesvmd@gmail.com (V.D. Alves).
}

fruits to be used, taking into account their physico-chemical and sensory properties and the characteristics of the desired final product.

Mango (Mangifera indica L.) is a popular and economically important tropical fruit throughout the world, due to its good texture, flavour, and high content of carotenoids, vitamin C, vitamin E, phenolic compounds, minerals and fibre, (Charles, Vidal, Olive, Filgueiras, \& Sallanon, 2013; Vijaya, Sreeramulu, \& Raghunath, 2010; Xiaolin et al., 2011). The consumption of mango can provide significant amounts of bioactive compounds with antioxidant activity. Its daily intake in the diet has been related to prevention of degenerative processes such as cardiovascular diseases and cancer (Alothman, Kaur, Fazilah, Bhat, \& Karim, 2010; Liu, 2003; SánchezRobles, Rojas-Graü, Serrano-Odriozola, Gonsalez-Aguilar, \& MartínBelloso, 2009).

Mango has been processed into a large variety of products, such as juices, powders, purees and dehydrated slices (Dak, Verma, \& Jaaffrey, 2007; Djantou, Mbofung, Scher, Phambu, \& Morael, 2011; Ledeker, Suwonsichon, Chamber, \& Adhikari, 2014; Sogi, Siddiq, \& Dolan, 2015; Sriwimon \& Boonsupthip, 2011). Furthermore, among the derivative mango products, mango bars or mango leathers are the most popular fruit bars in India. This mango bar is traditionally prepared by adding cane sugar, spreading the puree on bamboo mats and, drying it in the sun into 
leathery sheets (Vijayanand, Yadav, Balasubramanyan, \& Narasimham, 2000). In addition, mango gels were developed using processed commercial mango juice and sodium alginate, with the addition of a calcium source (calcium orthophosphate) and a calcium sequestrant (glucono- $\delta$-lactone) (Roopa \& Bhattacharya, 2014).

Gellan gum, a polysaccharide approved as a food additive which has been used in a wide variety of food products including confectionary, jams, jellies, fabricated foods, hydrogels, pie fillings, puddings, ice cream and yogurt (Lau, Tang, \& Paulson, 2000; Noda et al., 2008; Tang, Marvin, Tung, \& Zeng, 1996) was chosen as gelling agent for the fresh mango bars. The native polymer, high acyl (HA) gellan, is an extracellular hydrocolloid secreted by the bacterium Pseudomonas elodea, and its linear structure is based on the tetrasaccharide repeating unit $\rightarrow 4$ )-L-rhamnopyranosyl-(a-1 $\rightarrow 3$ )D-glucopyranosyl-( $\beta$-1 $\rightarrow$ 4)-D-glucoronopyranosyl-( $\beta$-1 $\rightarrow$ 4)-Dglucopyranosyl- $(\beta-1 \rightarrow$, with $\mathrm{O}(2)$ L-glyceryl and $\mathrm{O}(6)$ acetyl substituents on the 3-linked glucose (García, Alfaro, Calero, \& Muňoz, 2011; Noda et al., 2008; Yamamoto \& Cunha, 2007). When exposed to alkali at high temperature, the acyl groups are hydrolysed and the deacylated form, low acyl (LA) gellan, is obtained.

HA gellan hydration is inhibited by the presence of sugars and high $\mathrm{pH}$ values; therefore, the hydration must be carried out in presence of less than $40^{\circ}$ Brix total soluble solids content(TSS) and at $\mathrm{pH}$ values below 4 . By the contrary, LA gellan hydrates easily in the presence of sugars (up to $80^{\circ} \mathrm{Brix}$ TSS), being its hydration much more dependent on the ions concentration, and generally it is not complete at $\mathrm{pH}$ values below 4 (Philips \& Williams, 2009, chap. 9).

The gelation process of both gellan types is generally considered to involve two separate steps. In aqueous solutions, upon heating, the molecules of gellan are in a disordered coil state (single chain). Upon cooling the molecules adopt an ordered double helical conformation followed by associations between the helices through weak interactions such as hydrogen bonds and van der Waals forces (Matsukawa \& Watanabe, 2007; Nickerson, Paulson, \& Speers, 2003; Picone \& Cunha, 2010). In the case of LA gellan, the helices aggregation are also promoted by $\mathrm{pH}$ reduction or mediated by cations, either by site binding between pairs of carboxylate groups on neighbouring helices or by suppressing electrostatic repulsion by binding to individual helices (Morris, Nishinari, \& Rinaudo, 2012).

Generally, HA gels are thermally reversible without thermal hysteresis and set at temperatures around $70-80^{\circ} \mathrm{C}$; while the gel setting temperature of LA gels is around $30-50{ }^{\circ} \mathrm{C}$ showing significant thermal hysteresis, which extent is dependent on the nature and concentration of cations in solution (Philips \& Williams, 2000, chap. 7; Williams \& Philips, 1999; Rocha, Gonçalves, Bicho, Martins, \& Silva, 2014).

One of the major advantages of gellan gum relies on the ability of LA and HA to produce gels with quite different characteristics. HA gellan usually produces elastic, soft, non-brittle and opaque gels and LA gellan enables the formation of non-elastic, hard, brittle and transparent gels (Ogawa, Takahashi, Yajinma, \& Nishinari, 2006; Philips \& Williams, 2009, chap. 9). Therefore, a wide range of structures, with varied rheological properties, appealing textures and good flavour release, may be designed by controlling the acyl content. The development of texturized fruit bars involves the understanding of synergism between gellan gum and mango puree. The final structure and textural properties of these systems are strongly dependent on gellan physicochemical properties (e.g. acylation degree), $\mathrm{pH}$ and composition of the puree (e.g. sugars, cations and fibre content), as well as on processing conditions such as gellan concentration, LA/HA ratio and temperature.

The influence of the addition of gellan gum (different concentrations and LA/HA ratios) to the mango puree was evaluated through analysis of the rheological (small amplitude oscillatory shear measurements) and microstructural (confocal laser scanning microscopy) properties in order to develop a new fresh mango bar.

\section{Materials and methods}

\subsection{Materials}

Two types of commercial gellan gum were kindly supplied by CP Kelco Corporation, Wilmington, USA: low-acyl gellan gum (Kelcogel ${ }^{\circledR} \mathrm{F}$ ) and high-acyl gellan gum (Kelcogel ${ }^{\circledR} \mathrm{LT}$ ). The composition of gellan gum powder was supplied by the manufacturer. LA gellan: carbohydrate (dietary fibre) $82 \mathrm{~g} / 100 \mathrm{~g}$; moisture $7 \mathrm{~g} / 100 \mathrm{~g}$; $\mathrm{Ca}^{2+}$ $252 \mathrm{mg} / 100 \mathrm{~g}$; P $115 \mathrm{mg} / 100 \mathrm{~g} ; \mathrm{Fe}^{2+} 4 \mathrm{mg} / 100 \mathrm{~g} ; \mathrm{Mg}^{2+} 91 \mathrm{mg} / 100 \mathrm{~g}$, $\mathrm{Na}^{+} 478 \mathrm{mg} / 100 \mathrm{~g}$ and $\mathrm{K}^{+} 4650 \mathrm{mg} / 100 \mathrm{~g}$. HA gellan: carbohydrate (dietary fibre) $78 \mathrm{~g} / 100 \mathrm{~g}$; moisture $6 \mathrm{~g} / 100 \mathrm{~g} ; \mathrm{Ca}^{2+} 259 \mathrm{mg} / 100 \mathrm{~g}$; P $233 \mathrm{mg} / 100 \mathrm{~g} ; \mathrm{Fe}^{2+} 2 \mathrm{mg} / 100 \mathrm{~g} ; \mathrm{Mg}^{2+} 98 \mathrm{mg} / 100 \mathrm{~g}, \mathrm{Na}^{+} 510 \mathrm{mg} /$ $100 \mathrm{~g}$ and $\mathrm{K}^{+} 1930 \mathrm{mg} / 100 \mathrm{~g}$.

Mature mangoes ( $M$. indica L. cv. Palmer) were purchased from a local supermarket in Lisbon, Portugal and selected based on firmness and integrity.

\subsection{Methods}

\subsubsection{Preparation and analysis of fresh mango puree (control)}

Mangos were stored at $5 \pm 1{ }^{\circ} \mathrm{C}$ until processing (within $24 \mathrm{~h}$ ). The fruit was then washed under running water, and manually peeled with a knife, cut into small pieces, and pureed in a food blender Vorwerk Thermomix TM-31 at $134 \times \mathrm{g}$ for $4 \mathrm{~min}$ at $22 \pm 2{ }^{\circ} \mathrm{C}$.

2.2.1.1. Determination of ash content. The total ash content was determined according to AOAC Official Method 923.03 (AOAC, 1990). A mass of $5 \mathrm{~g}$ of mango puree was weighed into a shallow dish and subjected to a temperature of $5500^{\circ} \mathrm{C}$ until light a grey ash was produced. The dish was then cooled in a desiccator and weighed soon after reaching room temperature. The total ash content was calculated using eq. (1):

$\%$ Total ash $=\frac{\text { ash weight }}{\text { original sample weight }} \times 100$

2.2.1.2. Determination of mineral content. The ash obtained according the method described previously, was dissolved in $3 \mathrm{~mL}$ concentrated nitric acid and then diluted to $25 \mathrm{~mL}$ with deionized water. The solution obtained was used to determine the mineral content using an atomic absorption spectrophotometer (UNICAM M series, UK). Six types of minerals were determined, potassium, calcium, magnesium, sodium, and iron. Phosphorus was assayed colorimetrically based on the reaction of phosphate with molybdovanadate complex (Windham, 1995). The minerals content was expressed in $\mathrm{mg} / 100 \mathrm{~g}$ edible portion. The analysis was carried out in triplicate.

2.2.1.3. Determination of moisture content. A mass of $3 \mathrm{~g}$ of the mango puree $\left(w_{1}\right)$ was placed in the oven for $6 \mathrm{~h}$ at $105{ }^{\circ} \mathrm{C}$ (in triplicate). After drying, the dried sample was weighed $\left(w_{2}\right)$, and the moisture content was calculated using the following equation:

Moisture concent $(\%)=\frac{w_{1}-w_{2}}{w_{1}} \times 100$

2.2.1.4. Evaluation of $\mathrm{pH}$ and total soluble solids. The $\mathrm{pH}$ was determined using a $\mathrm{pH}$ meter BASIC $2^{\circ}$ CRISON, Spain, calibrated 
with standard buffers at 6.89 and 4.01. A digital refractometer PAL1, USA, calibrated with distilled water was used to determine total soluble solids (TSS). Each analysis was carried out in triplicate.

\subsubsection{Rheological measurements}

To perform the rheological measurements, sample preparation consisted on dispersing the required gellan powder into $20 \mathrm{~g}$ of puree, under stirring for $10 \mathrm{~min}$ on a magnetic plate stirrer at room temperature $\left(22 \pm 2{ }^{\circ} \mathrm{C}\right)$. Then, the sample was transferred to the rheometer plate where the jellification, gels maturation and mechanical properties determination took place. To study the effect of gellan concentration on the rheological properties of texturized mango puree, samples were prepared without gellan addition (control) and with $0.25,0.5,1.0$ and $2 \mathrm{~g}$ of gellan per $100 \mathrm{~g}$ of puree, either using LA or HA gellan.

To evaluate the effect of the LA/HA ratio on the rheological properties of the mango puree, samples were prepared in the same way without gellan (control) and with $1 \mathrm{~g}$ of gellan per $100 \mathrm{~g}$ of puree at LA/HA ratios: 100/0 (LA), 75/25, 50/50, 25/75 and 0/100 (HA).

Small amplitude oscillatory shear measurements were performed with a controlled Stress Rheometer, RS 75 Rheostress HAAKE, Germany, connected to a thermostatic bath for the temperature control. The samples were placed between two parallel stainless steel serrated plates with a diameter of $35 \mathrm{~mm}$, maintaining a constant gap of $1.0 \mathrm{~mm}$. Liquid paraffin was applied along the border of the plates to prevent sample dehydration.

To evaluate the gel setting temperature, the experimental procedure consisted on subjecting the samples to $90{ }^{\circ} \mathrm{C}$ for $1 \mathrm{~min}$, followed by temperature sweep of oscillatory measurement from $90{ }^{\circ} \mathrm{C}$ to $20^{\circ} \mathrm{C}$ at a rate of $1^{\circ} \mathrm{C} / \mathrm{min}, f=0.1 \mathrm{~Hz}$ and $\tau=1.0 \mathrm{~Pa}$. In the case of HA gellan, the temperature range was between $95{ }^{\circ} \mathrm{C}$ and $20^{\circ} \mathrm{C}$ in order to detect the gelling temperature. Immediately after the temperature sweep, time sweep of oscillatory measurements was used to investigate the change and the stability of the gels structure as a function of time. The maturation of the gels formed was monitored at $5{ }^{\circ} \mathrm{C}$ during $2 \mathrm{~h}$ at constant stress ( $\tau=1.0 \mathrm{~Pa}$ ) and frequency $(f=0.1 \mathrm{~Hz})$.

The samples were tested over a range of shear stresses. The stress sweep was applied under oscillatory shear of $f=0.1 \mathrm{~Hz}$ at $5{ }^{\circ} \mathrm{C}$ within a stress range between $\tau=10^{-1}$ and $10^{4} \mathrm{~Pa}$.

Afterwards, to determine the mechanical spectra, a new proportion of the same formulations were poured into the rheometer plate, first subjected to the temperature and time sweep tests described previously with the same oscillatory conditions. Frequency sweeps were conducted at $5{ }^{\circ} \mathrm{C}$, for frequency ranging from $10^{-2}$ to $10^{2} \mathrm{~Hz}$, with a constant shear stress within the linear viscoelastic region.

The frequency dependency was quantified from the $\beta$ exponent values obtained by fitting the power law regression $G^{\prime}\left(G^{\prime \prime}\right)=\alpha f^{\beta}$ (Valdez, Acedo-Carrilo, Rosas-Durazo, Lizardi, \& Goycoolea, 2006). Each experiment was carried out in triplicate and reproducible results were obtained.

\subsubsection{Confocal laser scanning microscopy analysis}

For confocal laser scanning microscopy analysis, mango bars were also prepared without gellan (control) and with $1 \mathrm{~g}$ of gellan per $100 \mathrm{~g}$ of puree at LA/HA ratios: 100/0 (LA), 75/25, 50/50, 25/75 and $0 / 100$ (HA).

The procedure consisted on transferring $80 \mathrm{~g}$ of the puree obtained into a $100 \mathrm{~mL}$ beaker, immersed in a boiling water bath (to prevent heat burn of the puree) on a heater/magnetic stirrer, and homogenizing it by stirring at $134 \times \mathrm{g}$. When the puree reached a temperature of $88 \pm 2{ }^{\circ} \mathrm{C}$, the required gellan gum was added, followed by increasing the rotation speed up to $1640 \times \mathrm{g}$ for $30 \mathrm{~s}$ in order to have a good dispersion and dissolution of the gellan powder. Afterwards, for the non-covalent labelling, fluorescent probe Fluoresceine $(0.1 \mathrm{~g}$ fluorescein $/ 500 \mathrm{~g}$ ) was added under stirring. The sample was then placed into rectangular silicon moulds ( $W \times H \times L=50 \times 10 \times 25 \mathrm{~mm}$ ) and allowed to set at room temperature $\left(22 \pm 2{ }^{\circ} \mathrm{C}\right)$, afterwards the samples were stored at $5^{\circ} \mathrm{C}$ for another $30 \mathrm{~min}$.

Confocal laser scanning microscopy (CLSM) of mango puree and thin slices of mango fruit bars with different LA/HA ratio was performed with a Leica TCS SP5, (Leica Microsystems, Mannheim, Germany) inverted confocal microscope using a $63 \times$ apochromatic water immersion objective lenses with a NA of 1.2 and an Argon laser for excitation. Fluorescence was analysed using a $488 \mathrm{~nm}$ excitation wave length and emission was collected between 510 and $670 \mathrm{~nm}$. The fluorescent probe, Fluorescein standard (Fluka, USA) was used for the non-covalent labelling of the mango puree and mango puree/gellan gum mixtures. The autofluorescence of mango puree was detectable in the same conditions. Microscopic observations were made at $20^{\circ} \mathrm{C}$ and digital image files were acquired with $2048 \times 2048$ pixels for a typical sample area of $246 \times 246 \mu \mathrm{m}$.

\section{Results and discussion}

\subsection{Composition of mango puree}

Among the minerals identified in mango puree, potassium was the one at higher concentration: $157.6 \pm 2.3 \mathrm{mg} / 100 \mathrm{~g}$. The concentration of the other minerals was: calcium $12.5 \pm 1.6 \mathrm{mg} / 100 \mathrm{~g}$; magnesium $9.4 \pm 0.8 \mathrm{mg} / 100 \mathrm{~g}$; phosphorus $8.4 \pm 2.3 \mathrm{mg} / 100 \mathrm{~g}$; sodium $2.2 \pm 1.8 \mathrm{mg} / 100 \mathrm{~g}$ and iron $2.6 \pm 0.6 \mathrm{mg} / 100 \mathrm{~g}$. The ash content was $300 \pm 25 \mathrm{mg} / 100 \mathrm{~g}$. The cation content of the mango puree and of both LA and HA gellan gum was enough to promote the gelation, as can be seen in the following sections. As such, there was no addition of external cations to the gellan/mango puree mixtures.

The water content was high $(81 \pm 0.03 \%)$, therefore, the hydration of gellan was promoted without the addition of water.

The TSS content of the mango puree used was $18.0 \pm 0.5^{\circ} \mathrm{Brix}$ whereas the $\mathrm{pH}$ was $4.3 \pm 0.3$. These values are in line with ideal conditions for the hydration of both LA and HA gellan: minimum $\mathrm{pH}$ value of 4 for LA gellan and TSS content below $40{ }^{\circ}$ Brix for HA gellan (Philips \& Williams, 2009, chap. 9).

\subsection{Viscoelastic properties of the control and mango puree/gellan systems}

This section is focused on the kinetics of gel network formation bearing in mind the different physicochemical characteristics of the two types of gellan referred in the literature (Huang, Tang, Swanson, \& Rasco, 2003; Mao, Tang, \& Swanson, 2000).

\subsubsection{Effect of concentration and type of gellan on the gelation} kinetics and viscoelastic properties of texturized mango puree

The effect of type of gellan and its concentrations on the variation of the storage $\left(G^{\prime}\right)$ and loss $\left(G^{\prime \prime}\right)$ moduli with temperature of mango puree/gellan mixtures is shown in Fig. 1.

Temperature sweeps indicated that all evaluated samples exhibited $G^{\prime}$ larger than $G^{\prime \prime}$ in whole temperature range, with no crossover between the moduli. The initial gelation temperature was defined as the one at which an increase of both moduli is observed, around $45 \pm 1.2^{\circ} \mathrm{C}$ for $0.25 \mathrm{~g} / 100 \mathrm{~g}$ of LA and $64 \pm 1.0^{\circ} \mathrm{C}$ for $2 \mathrm{~g} / 100$ $\mathrm{g}$ of LA. $G^{\prime}$ and $G^{\prime \prime}$ continued to increase with decreasing temperature achieving a maximum value equivalent to the final gelation temperature around $37.0 \pm 1.3{ }^{\circ} \mathrm{C}$ for $0.25 \mathrm{~g} / 100 \mathrm{~g}$ of $\mathrm{LA}$ and 

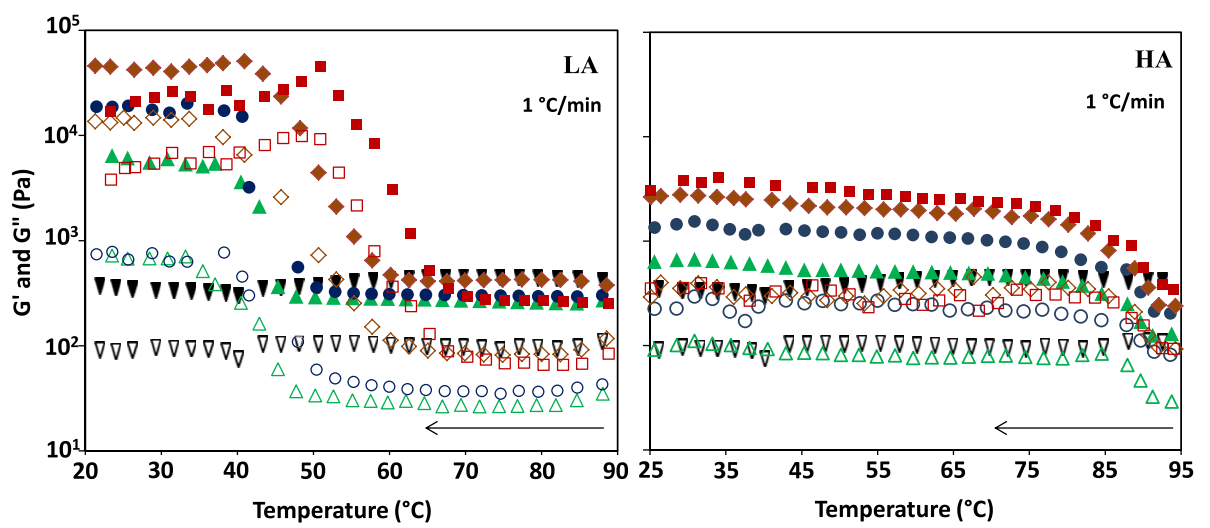

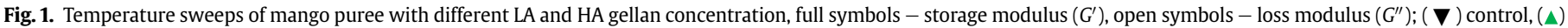
$0.25 \mathrm{~g} / 100 \mathrm{~g},(\bullet) 0.5 \mathrm{~g} / 100 \mathrm{~g},(\diamond) 1 \mathrm{~g} / 100 \mathrm{~g},(\square) 2 \mathrm{~g} / 100 \mathrm{~g}$.

$50 \pm 1.2{ }^{\circ} \mathrm{C}$ for $2 \mathrm{~g} / 100 \mathrm{~g}$ of LA. The initial and the final gelation temperatures became higher as the gellan concentration increased. In fact, the increase in polymer concentration offers more facility to establish intermolecular interactions, which is also in correlation with the increase of the dynamic moduli. For all gellan concentrations, the values of the moduli tend to a plateau after reaching a maximum value; this may be attributed to the formation of a fully developed internal network. It is interesting to note that a decrease of $G^{\prime}$ and $G^{\prime \prime}$ for temperatures below $50{ }^{\circ} \mathrm{C}$ for mango puree in the presence of $2 \mathrm{~g} / 100 \mathrm{~g}$ of LA gellan was observed (Fig. 1). This can be justified by the presence of fracture within the sample or slippage between the sample and the measuring geometry. Richardson and Goycoolea (1994) observed similar a behaviour with deacylated konjac glucomannan where the values of $G^{\prime}$ and $G^{\prime \prime}$ decreased during gelation. Further experiments are needed in order to confirm the presence of fracture and/or slippage.

The pectin molecules present in the mango puree are expected to play an important role on the gel formation kinetics and on the final gel characteristics. This may happen because both LA gellan and high methoxyl pectin form gels which properties are influenced by the presence of cations (e.g. calcium) (Basu \& Shivhare, 2010; Miyoshi \& Nishinari, 1999). Cations may suppress the electrostatic repulsions between the negative charge of pectin and gellan respectively, promoting gelation, and eventually the formation of a denser polymer network. However, further studies strictly focused on the interactions between both gellan types and pectin molecules in the presence of calcium are needed, to fully comprehend how the tridimensional carbohydrate network is formed within the complex system that is the mango puree.

When HA gellan was used as gelling agent, a slight increase of the moduli was noticed around $90{ }^{\circ} \mathrm{C}$ corresponding to the gelation temperature. A well-defined plateau is perceived for temperatures below $65{ }^{\circ} \mathrm{C}$ for all HA gellan concentrations tested, with the values of the moduli becoming higher as the polymer content increased (Fig. 1). For mango puree/HA systems, $\mathrm{Ca}^{2+}$ didn't play a similar role as in the case of LA gellan. More acyl groups lead to a greater interchain repulsion, therefore, less dense network formation with reduced vales of the moduli was noticed (Basu \& Shivhare, 2010).

Immediately after the temperature sweep, samples were cooled down to $5{ }^{\circ} \mathrm{C}$ at a rate of $1{ }^{\circ} \mathrm{C} / \mathrm{min}$ and the gel maturation kinetics of the samples were monitored through the evolution with time of $G^{\prime}$ and $G^{\prime \prime}$ moduli (Fig. 2). All the formulations with gellan gum reached the steady-state revealing constant values of both moduli. This information indicates that the gels formed have a stable and fully developed structure in 30 min of maturation. This fact is quite important, because it may increase significantly the fruit bars production rate at an industrial scale.

The structure of the mango puree (control) changes with time, the dynamic moduli shows a tendency to decrease after almost 90 min of maturation. This may be attributed to the thixotropic properties of mango puree where the increasing degree of structural breakdown with time is due to shearing (Bhattacharya, 1999). For this type of soft solids, rheological properties change not only with shear stress but also with time of shearing (Tiu \& Boger, 1974).
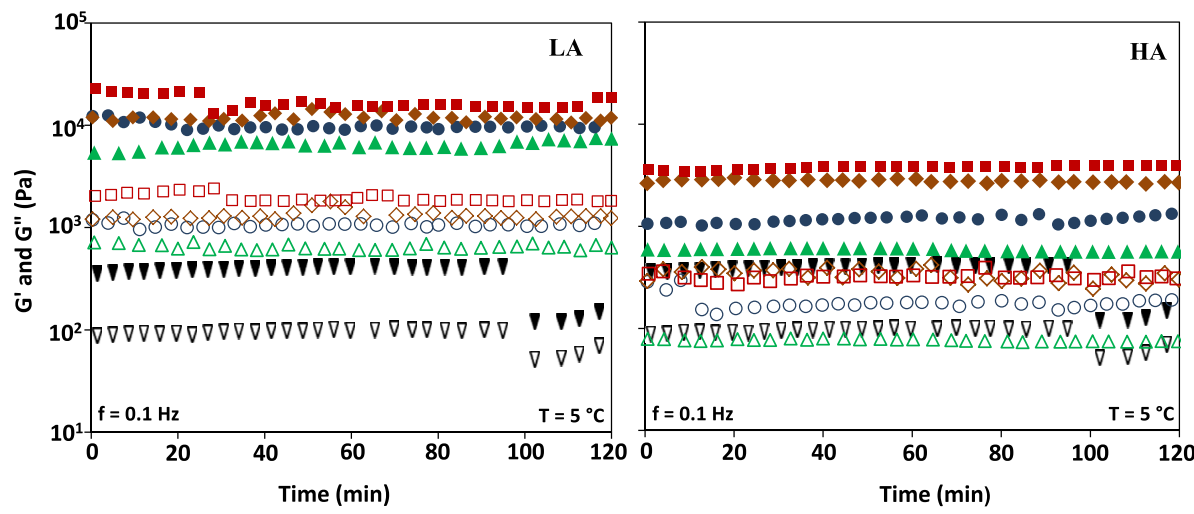

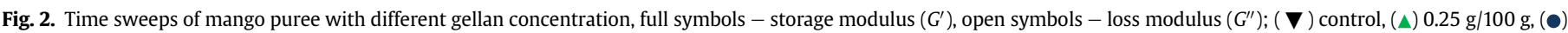
$0.5 \mathrm{~g} / 100 \mathrm{~g},(\$) 1 \mathrm{~g} / 100 \mathrm{~g},(\square) 2 \mathrm{~g} / 100 \mathrm{~g}$ 

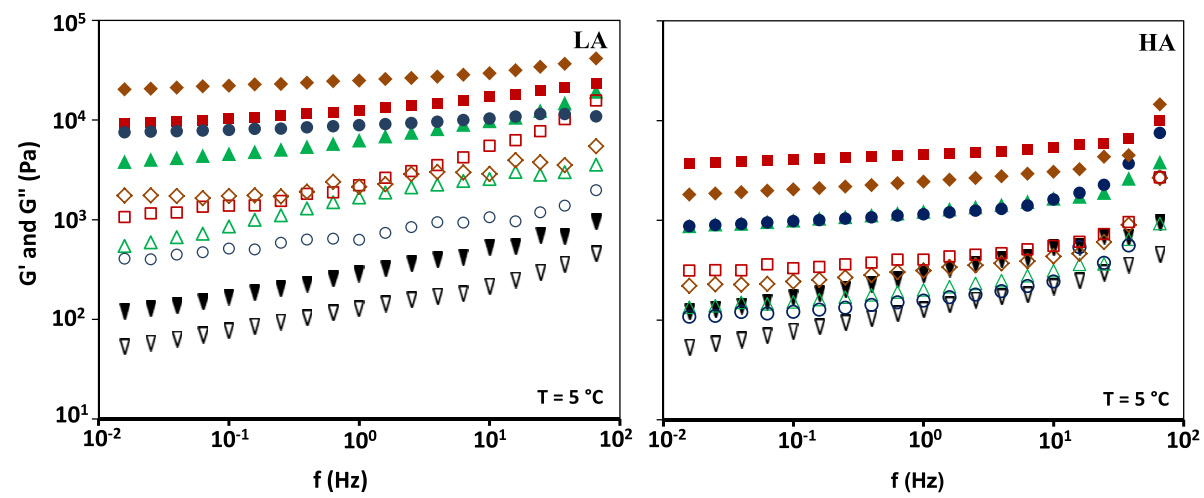

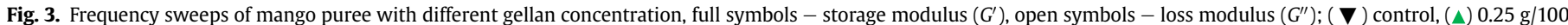
$\mathrm{g}$, (•) $0.5 \mathrm{~g} / 100 \mathrm{~g},(\diamond) 1 \mathrm{~g} / 100 \mathrm{~g},(\square) 2 \mathrm{~g} / 100 \mathrm{~g}$.

Fig. 3 shows the mechanical spectra of the mango puree (control) and texturized samples with different gellan concentrations. For the control, $G^{\prime}$ and $G^{\prime \prime}$ increased with increasing frequency with a high frequency dependence, were $G^{\prime}$ values are greater than $G^{\prime \prime}$ values through the whole range of frequencies studied. The ratio of $G^{\prime \prime}$ to $G^{\prime}(\tan \delta)$ is greater than 0.1 (results not shown) meaning that the mango puree could be characterized as having a behaviour of a weak gel. This type of behaviour has been reported by other authors for mango pulp (Iagher, Reicher, \& Ganter, 2002) and rice flour dispersions (Chun \& Yoo, 2004).

In the presence of gellan, all formulations exhibited a typical strong gel spectra, i.e. $G^{\prime}$ was always greater than $G^{\prime \prime}$ with a slight increase of the moduli as the frequency increased. In particular, both $G^{\prime}$ and $G^{\prime \prime}$ increased as LA concentration increased, indicating a reinforcement of the gel structure. The frequency dependence of the dynamic moduli tended to decrease as the LA concentration increased, which was quantified from the $\beta$ exponent values obtained by fitting the power law regression to experimental data (Table 1). Similar behaviour was observed for samples with HA gellan. For identical concentrations of LA and HA, lower dynamic values were observed for HA gels, which is consistent with their softer structure.

Overall, the addition of either LA or HA gellan to the mango puree improved significantly the viscoelastic properties, from the unstable and weak gel structure of the mango puree to a fully developed network with higher dynamic modulus and small frequency dependence.

Based on the mechanical spectra obtained for LA or HA/mango puree mixtures, the concentration of $1 \mathrm{~g} / 100 \mathrm{~g}$ enables the formation of gels with better viscoelastic properties than those with $0.5 \mathrm{~g} / 100 \mathrm{~g}$ of gellan. The values of the moduli for $1 \mathrm{~g} / 100 \mathrm{~g} \mathrm{LA} /$ mango puree mixtures were slightly higher than $2 \mathrm{~g} / 100 \mathrm{~g} \mathrm{LA} /$ mango puree, probably due an incomplete hydration of gellan gum when $2 \mathrm{~g} / 100 \mathrm{~g}$ LA was used. The water and cations content of the puree, along with the time of heating at $90{ }^{\circ} \mathrm{C}$, may not have been enough to completely hydrate the polymer, with consequences on the viscoelastic properties of the gel formed. Therefore, the gellan

Table 1

$\beta$ Values of the power law regression for different gellan concentrations.

\begin{tabular}{llllll}
\hline Gellan $(\mathrm{g} / 100 \mathrm{~g})$ & \multicolumn{2}{l}{ LA } & & \multicolumn{2}{l}{ HA } \\
\cline { 2 - 3 } \cline { 5 - 6 } & $\beta\left(G^{\prime}\right)$ & $\beta\left(G^{\prime \prime}\right)$ & & $\beta\left(G^{\prime}\right)$ & $\beta\left(G^{\prime \prime}\right)$ \\
\hline 0 & 0.23 & 0.23 & 0.23 & 0.23 \\
0.5 & 0.16 & 0.21 & 0.06 & 0.09 \\
1 & 0.10 & 0.12 & 0.10 & 0.09 \\
2 & 0.11 & 0.22 & 0.04 & 0.10 \\
\hline
\end{tabular}

concentration of $1 \mathrm{~g} / 100 \mathrm{~g}$ was selected to study the effect of LA/HA blends on the viscoelastic properties of the texturized product.

\subsubsection{Effect of $L A / H A$ ratios on the gelation kinetics and viscoelastic properties of mango puree}

A synergistic interaction exists between the native and deacylated gellan molecules upon gel formation when both gellan types are present in the system. Mao et al. (2000), reported that the weight ratio of LA/HA played a more important role in the textural properties of mixed gellan gels than the overall polymer concentration. Moreover, Morris, Gothard, Hember, Manning, and Robinson (1996) studied the LA/HA mixtures by Differential Scanning Calorimetry and observed two separate conformational transitions at temperatures characteristic of individual components. As such, there is the evidence of the establishment of zones within the gel network composed mainly by LA or HA molecules, connected to each other, enabling overall texture properties that cannot be obtained with only one type of gellan.

In order to design a wider range of mango bar samples with dissimilar textural properties, formulations containing varied LA/ HA ratios, maintaining constant the overall polymer concentration ( $1 \mathrm{~g} / 100 \mathrm{~g}$ ) were studied. The temperature sweeps of mango puree and LA/HA mixed gels (Fig. 4) presented similar behaviour to those described in Section 3.2.1. All the formulations showed $G^{\prime}$ larger than $G^{\prime \prime}$ in the whole temperature range studied. The initial gelation temperature for LA/HA gellan blends was around $60 \pm 1.1^{\circ} \mathrm{C}$ for $75 / 25,53 \pm 1.3^{\circ} \mathrm{C}$ for $50 / 50$ and $50 \pm 1.0{ }^{\circ} \mathrm{C}$ for $25 /$ 75. $G^{\prime}$ and $G^{\prime \prime}$ continued to increase with decreasing temperature reaching a maximum value equivalent to the final gelation temperature, $31 \pm 1.1{ }^{\circ} \mathrm{C}$ for $75 / 25,41 \pm 1.0{ }^{\circ} \mathrm{C}$ for $50 / 50$ and $40 \pm 1.1^{\circ} \mathrm{C}$ for $25 / 75$.

Time sweeps at $T=5{ }^{\circ} \mathrm{C}$ carried out immediately after the temperature sweeps, are presented in Fig. 5. All samples exhibited constant dynamic moduli during the entire time range studied showing rapid gel maturation.

Fig. 6 shows the mechanical spectra of mango puree gels prepared with the LA/HA blends. The increase of LA/HA ratio led to the increase of both $G^{\prime}$ and $G^{\prime \prime}$ while maintaining their slight dependency with the frequency, as illustrated by the small variation of $\beta$ exponent values, $0.06<\beta\left(G^{\prime}\right)<0.09$ and $0.11<\beta\left(G^{\prime \prime}\right)<0.13$ (Table 2). For all ratios used, texturized mango puree became less dependent with the frequency than the control. These mechanical spectra indicate gels with intermediate viscoelastic properties between those obtained with only LA or HA gellan.

Pectic polysaccharides are one of the prominent structural constituents in the mango fruit (Tharanathan, Yashoda, \& Prabha, 2006) and together with gellan gum can contribute to the stable 


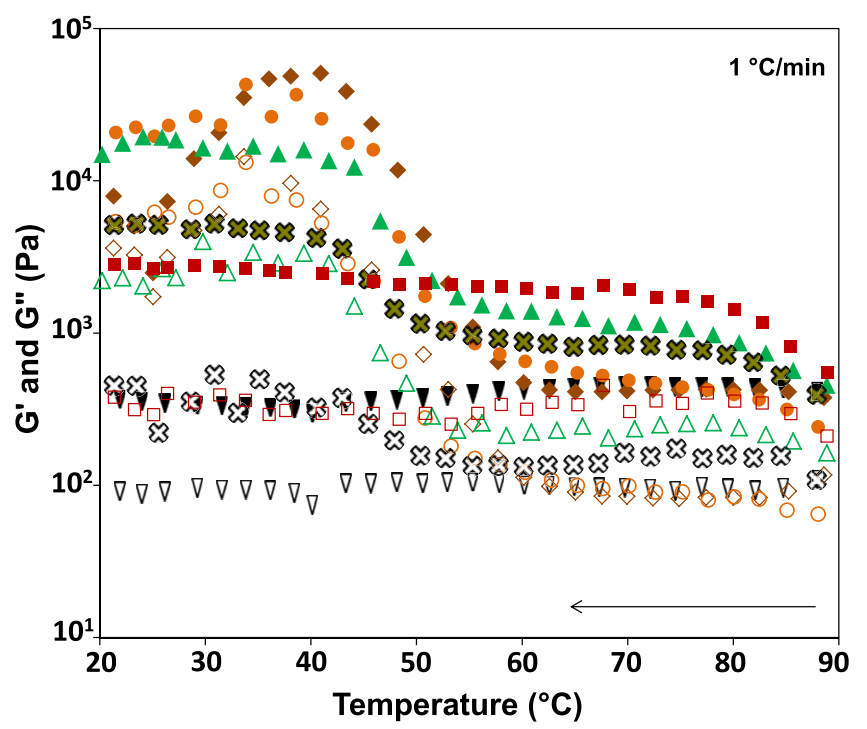

Fig. 4. Temperature sweeps of mango puree with LA, HA and different LA/HA gellan ratios for a fixed overall gellan concentration $(1 \mathrm{~g} / 100 \mathrm{~g})$; full symbols - storage

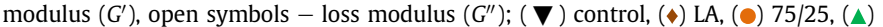
50/50, (§) 25/75, (ם) HA.

and well developed structure for the texturized mango puree. The addition of both gellan gum types into the mango puree overcomes the thixotropic character of the mango puree.

Overall, the results obtained from the small amplitude oscillatory shear measurements suggested that it is possible to create jellified mango bars, either by using different ratios of LA/HA gellan or LA and HA alone.

\subsection{Confocal laser scanning microscopy observations}

The structural organisation of the mango puree and mango bars was visualized by confocal laser scanning microscopy (CLSM). Microscopic observations of the mango puree with and without a fluorescent probe and that of stained mango puree/gellan gum

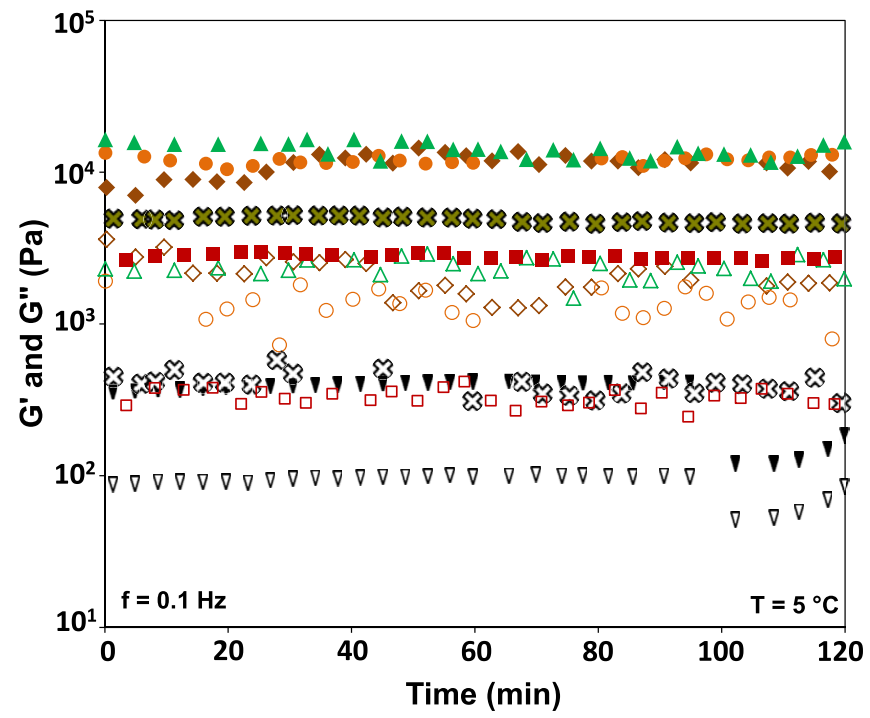

Fig. 5. Time sweeps of mango puree with LA, HA and different LA/HA gellan ratios for a fixed overall gellan concentration $(1 \mathrm{~g} / 100 \mathrm{~g})$; full symbols - storage modulus $\left(G^{\prime}\right)$

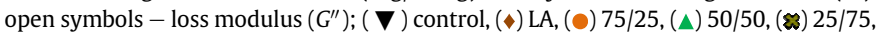
(a) HA.

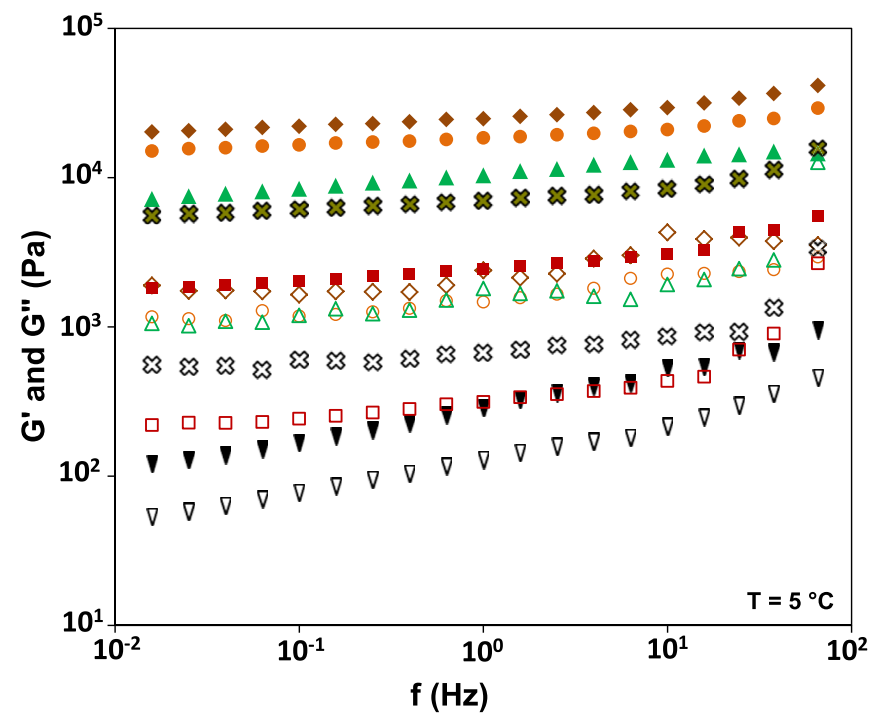

Fig. 6. Frequency sweeps of mango puree with LA, HA and different LA/HA gellan ratios for a fixed overall gellan concentration $(1 \mathrm{~g} / 100 \mathrm{~g})$; full symbols - storage

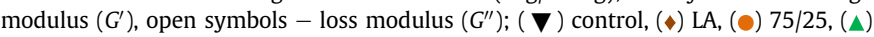
50/50, (æ) 25/75, (ם) HA.

mixtures ( $1 \mathrm{~g}$ of gellan per $100 \mathrm{~g}$ of puree) with LA, HA and LA/HA $(75 / 25,50 / 50$ and $25 / 75)$ ratios were performed at $20^{\circ} \mathrm{C}$.

Mango fruit is rich in dietary fibre (DF), such as insoluble dietary fibre (IDF): cellulose, hemicellulose, lignin; and soluble dietary fibre (SDF) mainly pectin (Tharanathan et al., 2006; Vergara-Valencia et al., 2007). Many publications have confirmed that different plant living cells containing insoluble dietary fibre (IDF) might exhibit intrinsic fluorescence (Roshchina, 2003). Fig. 7A show the microstructure of unstained mango puree with relatively weak intrinsic fluorescence where less aggregates with a bright green colour (in the web version) can be detected corresponding probably to the insoluble dietary fibre (IDF). When fluorescein was added to the samples, a contrast by differences in fluorescence, with intense fluorescent zones equivalent to several insoluble carbohydrates and less intense fluorescence zones, corresponding to the overall gel network of the mango bar may be observed.

For samples with LA, and, the mixture LA/HA 50/50, the distribution observed shows a similar pattern (Fig. 7C and D), resulting from the presence of aggregates surrounded by a continuous fluorescent phase, although there are large zones irregularly spread over the focal plane. This type of structure was also observed in the samples with formulations LA/HA 75/25 and 25/75 (results not shown) and represents a relatively homogeneous and well aggregated system.

The addition of $100 \%$ HA gellan to the mango puree resulted in a major change in the structural organisation of the sample. Fig. 7E shows a less dense network of the fluorescent mango puree/HA sample, indicating a weaker gel structure. Fig. 7B, corresponding to the stained mango puree, also shows a weak, less structured and deficiently aggregated gel structure. These results are in agreement

Table 2

$\beta$ Values of the power law regression for polymer at $1 \mathrm{~g} / 100 \mathrm{~g}$ with different LA/HA ratios.

\begin{tabular}{lll}
\hline LA/HA ratio & $\beta\left(G^{\prime}\right)$ & $\beta\left(G^{\prime \prime}\right)$ \\
\hline $100 / 0$ & 0.06 & 0.12 \\
$75 / 25$ & 0.06 & 0.11 \\
$50 / 50$ & 0.10 & 0.09 \\
$25 / 75$ & 0.07 & 0.08 \\
$0 / 100$ & 0.09 & 0.11 \\
\hline
\end{tabular}



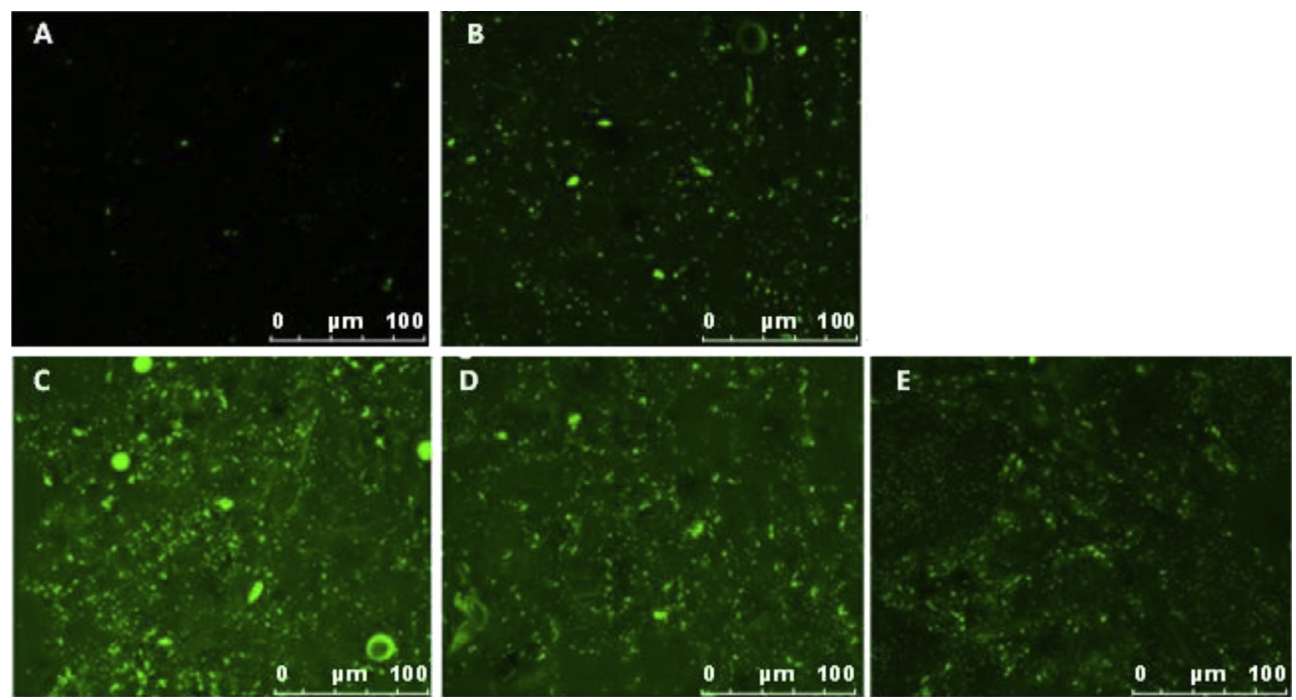

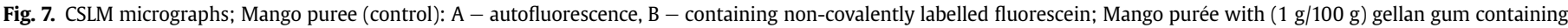
non-covalently labelled fluorescein C - LA, D - LA/HA 50/50, and E - HA gellan.

with rheological measurements where lower values of $G^{\prime}$ and $G^{\prime \prime}$ moduli were observed for these two systems. Clearly, the addition of LA gellan to the mango puree, results in more homogeneous and well aggregated systems which corresponds to the desirable structure for the product under development.

\section{Conclusions}

In this work, the gel forming kinetics and gel properties of gellan gum/mango puree mixtures were studied. The results show that chemical characteristics of the mango puree in terms of cations and water content, $\mathrm{pH}$ and TSS content are compatible with the hydration and gelation conditions required for the gelling agent. As referred in the literature (Bhattacharya, 1999; Iagher et al., 2002), mango puree shows thixotropic behaviour by decreasing the moduli with the lapse of time. The addition of LA, HA or LA/HA ratios to the mango puree improved its structure and produced texturized mango puree with interesting viscoelastic properties. Low maturation time (30 min) was needed for both LA and HA to reach a fully developed gel structure. For $1 \mathrm{~g} / 100$ g gellan concentration, LA gellan forms stronger structures than HA gellan. By using different LA/HA ratios for the same overall gellan concentration $(1 \mathrm{~g} / 100 \mathrm{~g})$, it was possible to produce texturized mango puree samples with intermediate viscoelastic properties, with a progressive rise of the dynamic moduli as the LA content increased.

CLSM observations also highlighted the formation of a denser structure for gels obtained with 100\% LA and LA/HA in different ratios, having the gels with only HA a more loosened structure. The overall results obtained suggest that it is possible to create mango bars structures with interesting designed rheological and microstructural properties by using LA/HA gellan mixtures. For the final development of the mango bars, these properties still need to be correlated to inputs from texture analysis and sensory evaluation as well as further microscopy techniques at smaller distance scales in order to obtain more microstructural and morphological information about these systems.

\section{Acknowledgements}

This paper is a result of the research within the Grant (SFRH/BD/ 64341/2009), financed by Fundação para a Ciência e Tecnologia.
These studies were supported by FCT-MCTES funding the projects PTDC/AGR-ALI/114706/2009 - "New edible bioactive coatings for the improvement of the fruit products quality" and PEst-OE/AGR/ UI0245/2014. The authors would like to thank to CP Kelco, Wilmington, USA for providing the gellan gum. The authors also acknowledge the Centro de Química Física Molecular of the Instituto Superior Técnico for the confocal microscopy studies and Dr Ermelinda Maçôas for guidance in the use of the equipment.

\section{References}

Ahvenainen, R. (1996). New approaches in improving the shelf life of minimally processed fruit and vegetables. Trends in Food Science and Technology, 7, $179-187$.

Alothman, M., Kaur, B., Fazilah, A., Bhat, R., \& Karim, A. A. (2010). Ozone-induced changes of antioxidant capacity of fresh-cut tropical fruits. Innovative Food Science and Emerging Technologies, 11, 666-671.

AOAC. (1990). In K. Helrich (Ed.), Official methods of analysis (15th ed.). Arlington, VA, USA: Association of Official Analytical Chemists, Inc.

Basu, S., \& Shivhare, U. S. (2010). Rheological, textural, micro-structural and sensory properties of mango jam. Journal of Food Engineering, 100, 357-365.

Bhattacharya, S. (1999). Yield stress and time-dependent rheological properties of mango pulp. Food Engineering and Physical Properties, 6, 1029-1033.

Charles, F., Vidal, V., Olive, F., Filgueiras, H., \& Sallanon, H. (2013). Pulsed light treatment as new method to maintain physical and nutritional quality of freshcut mangoes. Innovative Food Science \& Emerging Technologies, 18, 190-195.

Chun, S. Y., \& Yoo, B. (2004). Rheological behaviour of cooked rice flour dispersion in steady and dynamic shear. Journal of Food Engineering, 65, 363-370.

Corbo, M. R., Lanciotti, R., Gardini, F., Sinigaglia, M., \& Guerzoni, M. E. (2000). Effects of hexanal, trans-2-hexenal, and storage temperature on shelf-life of fresh sliced apples. Journal of Agricultural and Food Chemistry, 48, 2401-2408.

Dak, M., Verma, R. C., \& Jaaffrey, S. N. A. (2007). Effect of temperature and concentration on rheological properties of "Kesar" mango juice. Journal of Food Engineering, 80, 1011-1015.

Djantou, E. B., Mbofung, C. M. F., Scher, J., Phambu, N., \& Morael, J. D. (2011). Alternation drying and grinding (ADG) technique: a novel approach for producing ripe mango powder. LWT - Food Science and Technology, 44, 1585-1590.

García, M. C. Alfaro, M. C., Calero, N., \& Muňoz, J. (2011). Influence of gellan gum concentration on the dynamic viscoelasticity and transient flow of fluid gels Biochemical Engineering Journal, 55, 73-81.

Huang, Y., Tang, J., Swanson, B. G., \& Rasco, B. A. (2003). Effect of calcium concentration on textural properties of high acyl and low acyl mixed gellan gels. Carbohydrate Polymers, 54, 517-522.

lagher, F., Reicher, F., \& Ganter, J. L. M. S. (2002). Structural and rheological properties of polysaccharides from mango (Mangifera indica L.) pulp. Biological Macromolecules, 31, 9-17.

Lau, M. H., Tang, J., \& Paulson, A. T. (2000). Texture profile and turbidity of gellan gelatin mixed gels. Food Research International, 33, 665-761.

Ledeker, C. N., Suwonsichon, S., Chamber, D. H., \& Adhikari, K. (2014). Comparison of sensory attributes in fresh mangoes and heat-treated mango purées prepared from Thai cultivars. LWT - Food Science and Technology, 56, 138-144. 
Liu, R. H. (2003). Health benefits of fruit and vegetables are from additive and synergistic combinations of phytochemicals. The American Journal of Clinical Nutrition, 78, 517S-520S

Mao, R., Tang, J., \& Swanson, B. G. (2000). Texture properties of high and low acyl mixed gellan gels. Carbohydrate Polymers, 41, 331-338.

Matsukawa, S., \& Watanabe, T. (2007). Gelation mechanism and network structure of mixed solution of low-acyl and high-acyl gellan studied by dynamic viscoelasticity, CD and NMR measurements. Food Hydrocolloids, 21, 1355-1361.

Miyoshi, E., \& Nishinari, K. (1999). Rheological and thermal properties near the sol-gel transition of gellan gum aqueous solutions. Progress in Colloid and Polymer Science, 114, 68-82.

Morris, E. R., Gothard, M. G. E., Hember, M. W. R., Manning, C. E., \& Robinson, G. (1996). Conformational and rheological transitions of wellan, rhamsan and acylated gellan. Carbohydrate Polymers, 30, 165-175.

Morris, E. R., Nishinari, K., \& Rinaudo, M. (2012). Gelation of gellan - a review. Food Hydrocolloids, 28, 373-411.

Nickerson, M. T., Paulson, A. T., \& Speers, R. A. (2003). Rheological properties of gellan solutions: effect of calcium ions and temperature on pre-gel formation. Food Hydrocolloids, 17, 577-583.

Noda, S., Funami, T., Nakauma, M., Asai, I., Takahashi, R., Al-Assaf, S., et al. (2008). Molecular structure of gellan gum imaged with atomic force microscopy in relation to the rheological behaviour in aqueous systems. 1. Gellan gum with various acyl contents in the presence and absence of potassium. Food Hydrocolloids, 22, 1148-1159.

Ogawa, E., Takahashi, R., Yajinma, H., \& Nishinari, K. (2006). Effects of molar mass on the coil to helix transition of sodium-type gellan gums in aqueous solutions. Food Hydrocolloids, 20, 378-385.

O'Shea, N., Arendt, E. K., \& Gallagher, E. (2012). Dietary fibre and phytochemica characteristics of fruit and vegetables by-products and their recent applications as novel ingredients in food products. Innovative Science \& Emerging Technologies, 16, 1-10.

Philips, G. O., \& Williams, P. A. (2000). Handbook of hydrocolloids. England.

Philips, G. O., \& Williams, P. A. (2009). Handbook of hydrocolloids (2nd ed). England.

Picone, C., \& Cunha, R. S. (2010). Interactions between milk proteins and gellan gum in acidified gels. Food Hydrocolloids, 24, 502-511.

Richardson, R. K., \& Goycoolea, F. M. (1994). Rheological measurement of kappacarrageenan during gelation. Carbohydrate Polymers, 24, 223-225.

Rocha, L. A., Gonçalves, A. I. C., Bicho, D., Martins, R., \& Silva, F. (2014). Screening of gellan gum as an ionic and hydrophobic chromatographic matrix for biomolecules purification. Separation and Purification Technology, 132, 452-460.

Roopa, B. S., \& Bhattacharya, S. (2014). Mango gels: characterization by smalldeformation stress relaxation method. Journal of Food Engineering, 131, 38-43.

Roshchina, V. V. (2003). Autofluorescence of plant secreting cells as a biosensor and bioindicator reaction. Journal of Fluorescence, 13, 403-420.
Sánchez-Robles, R. M., Rojas-Graü, M. A., Serrano-Odriozola, I., GonsalezAguilar, G. A., \& Martín-Belloso, O. (2009). Effect of minimal processing on bioactive compounds and antioxidant activity of fresh-cut "Kent" mango (Mangifera indica L.). Postharvest Biology and Technology, 51, 384-390.

Schieber, A., Wieland, U., \& Reinhold, C. (2000). Characterisation of polyphenols in mango puree concentrate by HPLC with diode array and mass spectrometric detection. Innovative Food Science \& Emerging Technologies, 1, 161-166.

Sogi, D. S., Siddiq, M., \& Dolan, K. D. (2015). Total phenolics, carotenoids and antioxidant properties of Tommy Atkin mango cubes as affected by drying techniques. LWT - Food Science and Technology, 62(1), 564-568. http://dx.doi.org/ 10.1016/j.lwt.2014.04.015.

Sriwimon, W., \& Boonsupthip, W. (2011). Utilization of partially ripe mangoes for freezing preservation by impregnation of mango juice and sugars. LWT - Food Science and Technology, 44, 375-383.

Tang, J., Marvin, A., Tung, A., \& Zeng, Y. (1996). Compression strength and deformation of gellan gels formed with mono- and divalent cations. Carbohydrate Polymers, 29, 11-16.

Tharanathan, R. N., Yashoda, H. M., \& Prabha, T. N. (2006). Mango (Mangifera indica L.), "the king of fruits" - an overview. Food Reviews International, 22, 95-123.

Tiu, C., \& Boger, D. V. (1974). Complete rheological characterization of time dependent food products. Journal of Texture Studies, 5, 328-338.

Valdez, M. A., Acedo-Carrilo, J. I., Rosas-Durazo, A., Lizardi, R. M., \& Goycoolea, F. M. (2006). Small deformation rheology of mesquite gum stabilized oil in water emulsions. Carbohydrate Polymers, 64, 205-211.

Vergara-Valencia, N., Granados-Perez, E., Agama-Acevedo, E., Tovar, J., Ruales, J., \& Bello Perez, L. A. (2007). Fibre concentrate from mango fruit: characterisation, associated antioxidant capacity and application as a bakery product ingredient. LWT - Food Science and Technology, 40, 722-729.

Vijaya, K. R., Sreeramulu, C., \& Raghunath, D. M. (2010). Antioxidant activity of fresh and dry fruits commonly consumed in India. Food Research International, 43, 285-288.

Vijayanand, P., Yadav, A. R., Balasubramanyan, N., \& Narasimham, P. (2000). Storage stability of guava fruit bar prepared using a new process. LWT - Food Science and Technology, 33, 132-137.

Williams, P. A., \& Philips, G. O. (1999). Gums and stabilizers for the food industry. Cambridge, UK: Royal Society of Chemistry.

Windham, W. R. (1995). Official methods of analysis of AOAC International (16th ed.).

Xiaolin, Z., Guoxing, J., Yan, L., Tianjia, J., Yueming, J., \& Jianrong, L. (2011). Expression of expansin gene, MiExpA1, and activity of galactosidase and polygalacturonase in mango fruit as affected by oxalic acid during storage at room temperature. Food Chemistry, 132, 849-854.

Yamamoto, F., \& Cunha, R. L. (2007). Acid gelation of gellan: effect of final pH and heat treatment conditions. Carbohydrate Polymers, 68, 517-527. 